\title{
INFORMATION TECHNOLOGY AND RISK FACTORS FOR EVALUATING THE BANKING INDUSTRY IN THE TAIWAN: AN APPLICATION OF A VALUE CHAIN DEA
}

\author{
Mu-Shun WANG ${ }^{1}$, Shih-Tong LU $^{2}$ \\ 1,2 Department of Banking and Finance, Kainan University, Luzhu, Taoyuan, Taiwan \\ ${ }^{2}$ Department of Business Administration, National Central University, Jhongli, \\ Taoyuan, Taiwan \\ E-mails: ${ }^{1}$ ruffinwang@yahoo.com.tw (corresponding author); \\ ${ }^{2}$ stonelu8604@gmail.com
}

Received 02 July 2013; accepted 09 October 2014

\begin{abstract}
The main purpose of the paper is utilizing a new tool to measure the marginal benefits of information technology on productivity based upon identifying the two-stage best practice frontier. This study utilizes value-chain data envelopment analysis to investigate the effects of Information Technology and the trading activities of financial derivatives on the technical efficiency of a bank's production process through a two-stage analytical study with a firm-level data set. We find the impact of indicators related to capital adequacy ratios, exchange rate volatility, interest rate volatility, and long-term loans in relation to capital and ownership structure. Technical efficient precedes a reduction in problem loans, concentration of the operating units and developing information technology and utilization of financial derivatives. This paper provides a theoretical rationale and conceptualizing risk factors with environmental uncertainty. The innovation variables are determinants of the bank efficiency on Basel III Accord.
\end{abstract}

Keywords: efficiency, Basel III Accord, Value-Chain DEA, financial derivatives, Tobit regression, commercial banks, problem loan.

JEL Classification: D61, G21, G34.

\section{Introduction}

We examine banking data for a 5-year period (2008-2012). Our results remain unchanged even after controlling for the long-term loan to capital (LCR), capital adequacy ratio (CAR), exchange rate volatility (ERV), and interest rate volatility (IRV). Overall, the results indicate that the improvement in efficiency seen after the global banking crisis is possibly due to the enhancement of non-interest income-based activities and financial innovation as a consequence of lower LCRs, higher CARs, ERV and stabilized support from ownership such as state-owners (SOE) or merging with the financial holding subsidiaries (FHS). This study adapts new concepts which incorporate IT inputs and risk factors to evaluate bank efficiency. We measure the DEA efficiencies using the 
CCR model in stage one and adjusted inputs in the BCC model as stated in stage two of the proposed model. From the Tobit regression in the second stage, we obtain the technical efficiency (TE), scale efficiency (SE) and pure technical efficiency (PTE). We confirm that the moral hazard hypothesis and the bad risk management hypothesis for the improvement of managerial efficiency are associated with non-interest income-based activities arising from FI such as the amount trading of financial derivatives (hereafter ATFD).

\section{IT inputs and risk factors in evaluating for CB efficiency}

In today's world, information technology (IT) is reengineering the competitive environment in which a business operates and competes (Shao, Lin 2002), and the IT-related value-added activities identify its effects on intermediate output variables to bank performance and then evaluated the marginal benefits of IT (Wang et al. 1997; Chen, Zhu 2004; Liu et al. 2013). Kao (2014) discussed using a network DEA model to assess the impact of IT on the banking industry using variables similar variables to those of Chen and Zhu (2004). They also used a similar model (two-stage DEA) to find the overall efficiency of non-life insurance companies (Kao, Hwang 2008). Fukuyama and Weber (2010), Akther et al. (2012) also employed similar model that lacked IT input, but included non-performing loans), while Gaganis et al. (2009) explored branch profitability with provision for loan loss. They treated production processes as a black box in their debate of the traditional DEA, ignoring what goes on inside the box such as a network system. Our study extends their findings and further measures efficiency in uncertain environments when resources are being shared in order to obtain a better assessment.

The non-performing loan (NPL) of CBs has been steadily increasing over the past decade and profitability has been declining since the 1997 Asian financial crisis. Such problem loans incur increased labor and administrative costs and loan output is required for the adjustment of risk management, risk-based capital requirements have changed, leading to a reduction in the optimal bank size needed to achieve maximum scale and scope economies (Lieu et al. 2005), that the geographical location of the bank does not seem to be related to either its profitability or marketability efficiency, and overall efficiency can predict the likelihood of bank failure (Luo 2003). Some large CBs that were previously efficient have become too large and thus less efficient. It can also be seen that the decline in interest margins induced by greater competition has encouraged CBs to charge higher fees for both existing and new services. However, as noted by Lepetit et al. (2008), higher reliance on non-interest generating activities is associated with higher risk and profit is more strongly correlated with commission and fee income than trading activities. CB bears higher risk demonstrates superior performance, implying praise for risky behaviour (Chen 2012). However, the Basel III has introduced explicit capital requirements for liquidity risk, leadings CBs to set stricter acceptance criteria (Bolt, Tieman 2004).

The contributions of FI, such as the creation of financial derivatives, cannot be directly measured with available bank-level data. Attracting new customers, IT is rapidly in- 
creasing market share in the banking system and helping to generate profitable noninterest activities, while at the same time the problem of NPL has caused a decline in the traditional operating activities. The assessment of CBs has always been a major research item in the marketing and related fields. The issue of the efficiency of a bank's marketing processes and their relationship with their customers through the IT and FI is central to its ability to gain a competitive edge vis-à-vis its rivals.

\subsection{Research design and hypotheses}

High CBs with high capital adequacy would have no reason to engage in business with high risks, leading to the high efficiency of CBs in the long run (moral hazard hypothesis), the sequential research in the risk factors in Chiu et al. $(2008,2011)$ and Ebrahimnejad et al. (2014), which can be regarded as an indicator of goodwill, an intangible asset, and enlarge the number of branches (local banks have insufficient distributions) in their argument.

H1: More fund inputs and IT inputs are positively related to the performance of marketability in the value-chain stages.

H1a: The LCR is negatively related to TE, SE and PTE.

H1b: The CAR is positively related to TE, SE and PTE.

The provision of loan loss and allowance of loan loss may arise when the financial market is unstable and the expected return has higher volatility (bad risk management hypothesis). One needs to consider the environmental risks in the financial market. Greater volatility means that the customer needs to hedge their speculative behavior (Berger, DeYoung 1997; Cook et al. 2014).

H2: Greater volatility affects operating performance in the value chain DEA.

H2a: Greater ERV is positively related to TE, SE and PTE.

H2b: Greater IRV is negatively related to TE, SE and PTE.

Several papers estimating managerial inefficiency by accounting for the exogenous impacts, such as the impacts of location, market power, regulations, organization, and new technologies (Paradi, Zhu 2013). Chen (2012) found that a concrete risk indicator has sufficient coverage of the banking businesses is still lacking, we concerns the financial stability of the international financial system, which would diminish the operational applicability and popularized worth, the ATFD and NPLs is included. Operation of the banking system is highly external and is directly impacted by the volatility of the economic structure in terms of FI and competition. The positive relationship between the Basel III Accord restrictions and ATFD simply reflects the effects of significant efficiency variables. Some studies have used the NPL as a measure of the credit risk. Chang and Chiu (2006) viewed risks as an undesired output and evaluation of cost efficiency for DMUs in the first stage (Chen 2012).

The Basel III puts emphasis on the CAR to engage in a broad range of activities closely associated with less concentration, more competition and greater securities market development for commercial banks. Generally speaking, a higher CAR will result in a 
smaller tax deduction (Drake, Hall 2003; Banker et al. 2010) or a lower risk with a higher proportion of equity to debt (Park, Weber 2006) which acts to increase risktaking behavior (Barth et al. 2004). This leads to more stringent and higher initial capital requirements which can impose entry barriers for new entrants and higher overall capital requirements associated with higher fixed costs for running the bank (Agoraki et al. 2011) meaning that fewer CBs are able to afford these costs.

\subsection{Evaluation methods}

The two-stage model of the production process is a method that combines two separate linear programs into a single linear program, thus called the value chain of the DEA model (Wang et al. 1997; Chen, Zhu 2004, Paradi, Zhu 2013). It is assumed that the overall efficiency of the two-stage process is a weighted sum of efficiencies acquired in the individual stage. Consider that production can be separated into two processes, the network system has $\mathrm{X}$ inputs to produce the intermediate product 2, which is produced by the first stage, and can be utilized by the second stage. The value chain model is depicted in Figure 1.

The overall efficiencies of the network for converting $\mathrm{X}$ to $\mathrm{Y}$ (profitability), that of generating the first stage for converting $X$ to $Z$, and that of generating the second stage for converting $\mathrm{Z}$ to $\mathrm{Y}$ can be calculated independently by applying the CCR model (Charnes et al. 1978).

Figure 2 shows the two-stage system series, Kao and Hwang (2010) suggested the use of rational models for series and parallel structures, and that the aggregated output be less than or equal to the aggregated input for all stages; see Figure 2. Kao and Hwang argued that "when the processes are connected in a series the system efficiency is the product of the process efficiencies of the relational model" to keep this property. The inputs for the IT budgets are shared with process 1 . We have not separated the estimates of the IT input in the chain-value DEA that differ from those of Kao and Hwang (2010). The increase is clearly due to the contribution of IT to the process 1 operations. We argue that IT impact is directly related to performance. The two-stage production process is connected to the intermediate product, financial derivatives, deposits and liabilities,
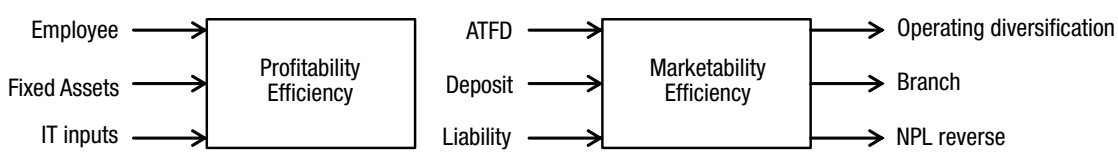

Fig. 1. The two-stage DEA

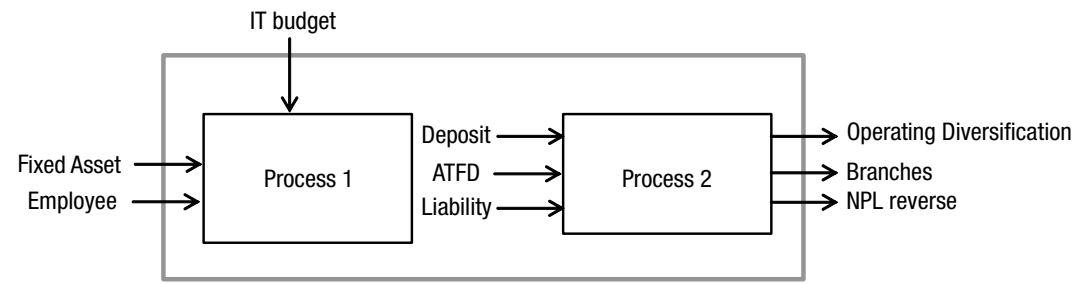

Fig. 2. IT budget with performance in the chain-value 
which need to be traded and news is disclosed through the e-commerce, ATM, internet, and SWIFT network system. Figure 2 provides a better illustration of the performance of the two processes, fund collection and profit generation, and a clearer picture of the impact of IT inputs on profitability and, through the intermediaries, on marketability.

\subsection{Variable construction}

Under an intermediation approach setting, appropriate inputs are measurements that the DMUs would like to minimize, while outputs are the measures that DMUs would like to maximize. Those input/output variables are defined in the two-stages on the Table 1. Employees, fixed asset and IT inputs can be used to determine value chain inefficiency relative to the size of the bank. It has been assumed in several studies that IT exclusively impacts bank performance indirectly through fund collection. IT is applied to collect funds from bank customers in the form of deposits which have been invested in ATFD and provided for loans. Due to a lack of information on how IT budgets were spent, we followed the methodology of Kao and Hwang (2010); we assume that a bank utilizes a proportion of the IT budget for stage 1. We allowed each bank to select the most favourable in calculating the system efficiency in order to collect the voices of manager who serves as the IT department from the true source of information. The number of ATMs is used as a proxy for IT budgets, because the ATM is necessary for the use of information technology in the operating activities from headquarters to branches.

Table 1. Definitions and source of variables

\begin{tabular}{ll}
\hline \multicolumn{1}{c}{ Variables } & \multicolumn{1}{c}{ Definition } \\
\hline Number of employees $^{\mathrm{N}}$ & Number of employees at the end of the year \\
\hline IT inputs (Budget\$) & $\begin{array}{l}\text { Information technology expenditure annual (estimated for survey } \\
\text { on bank's manager) }\end{array}$ \\
\hline $\left.\begin{array}{l}\text { IT inputs } \\
(\text { ATM }\end{array}\right)$ & $\begin{array}{l}\text { Proxy for information technology budget because for using web } \\
\text { and transmission tools }\end{array}$ \\
\hline Fixed assets\$ & Value of real estate, property, structures and equipment \\
\hline ATFD\$ & Amount of trading by financial derivatives \\
\hline Deposit\$ & Amount of saving account deposits per year \\
\hline Liability\$ & Liability of raised funds \\
\hline NPL reverse\$ & Nonperforming loan has recovered \\
\hline OD\% & Operating diversification \\
\hline Branch ${ }^{\mathrm{N}}$ & Number of subsidiary units \\
\hline ERV@ & Exchange rate volatility \\
\hline CAR\% & Capital adequacy ratio \\
\hline INV@ & Interest volatility \\
\hline LCR\% & Long-term loan to capital \\
\hline
\end{tabular}

Notes: The data are acquired from annual reports released by the Securities and Future Commission (SFC) of the Taiwan ROC as well as balance sheets and income statements obtained from the Taiwan Economic Journal database. \$: NT\$ million; N: numbers;\%: ratio; @: coefficient. 
In the intermediary stage of the inputs (profitability stage of outputs), we choose three output factors for our estimation of the marketability stage, branch, NPL reverse and Operating Diversification (OD). The degree of OD is calculated as follows:

$$
O D=\left(\frac{T N O R_{t}-T O E_{t}-L L P_{t}}{B V_{t}}\right) \bullet(1-T)-C E,
$$

where BV means book value, TNOR means total net operating revenues, total operating expenses are TOE, loan loss provisions (LLP) and capital cost (CE), corporate tax rate (T). Branch captures the fundamental contribution in the marketability stage of the bank's internal operating process, and provides management improvement guidelines by identifying the practices associated with customer relations. Deposits and liabilities function as an input in determining the efficiency of the financial institution (Sealey, Lindley 1977). Our exploration on the data in relation to deposits is slightly inconsistent with Glass's et al. (1998) findings. Akther et al. (2012) treated bad loans that were generated in the first-stage and input into the second-stage as an undesirable output with an assumption of weak disposability, which can be reduced.

\section{Value-Chain DEA model}

Let $X_{i j}$ and $Y_{r j}$ denote the ith input, $i=1, \ldots, m$, and $r^{\text {th }}$ ouput, $r=1, \ldots, s$. respectively. We denote the set of $j^{\text {th }}$ DMUs as $j=1, \ldots, n$. The constant returns to scale (CRS) efficiency scores can be calculated with the cost minimization model, expressed as in Eq. (1). Eq. (2) shows VRS model (Banker et al. 1984):

Subject to (stage 1)

$$
\operatorname{Min}_{\alpha, \beta, \lambda_{j}, \mu_{j}, \tau} \omega_{1} \alpha-\omega_{2} \beta
$$

$$
\begin{aligned}
& \sum_{j=1}^{n} \lambda_{j} x_{i j} \leq \alpha x_{i j 0}, i=1, \ldots, m, \\
& \sum_{j=1}^{n} \lambda_{j} z_{d j} \geq \tilde{z}_{d j 0}, d=1, \ldots, D, \\
& \sum_{j=1}^{n} \lambda_{j}=1 \\
& \lambda_{j} \geq 0, j=1, . ., n
\end{aligned}
$$

Subject to (stage 2)

$$
\begin{aligned}
& \sum_{j=1}^{n} \mu_{j} z_{d j} \leq \tilde{z}_{d j 0}, d=1, \ldots, D, \\
& \sum_{j=1}^{n} \mu_{j} y_{r j} \geq \beta y_{r j 0}, r=1, \ldots, s, \\
& \sum_{j=1}^{n} \mu_{j}=1, \\
& \mu_{j} \geq 0, j=1, \ldots, n,
\end{aligned}
$$


where $\omega_{1}$ and $\omega_{2}$ are user-specified weights, and $\omega_{1}+\omega_{2}=1$. By virtue of the optimization process, it can turn out that either $\omega_{1}=1$ and $\omega_{2}=0$ or $\omega_{1}=0$ and $\omega_{2}=$ 1 at optimality. Let $X_{i j}$ and $Y_{r j}$ be the amount of ith input consumed and the amount of $r^{\text {th }}$ output produced by the $j^{\text {th }}$ bank, respectively. For marketability efficiency, the total number of observations $(n)$ is DMUs, where $i$ is equal to three inputs (employees, fixed assets and IT budget), and $j$ equals three outputs (liabilities, deposits, ATFD). For marketability efficiency, $\mathrm{n}$ is equal to DMUs, where $i$ is equal to three inputs (liabilities, deposits, ATFD), and $j$ is equal to three outputs (branches, NPL revealed, OD).

To test the hypotheses, we examine the effects of IT inputs and ATFD on CBs efficiency. A Tobit regression is used on the panel data sample to account for the censoring of the dependent variables. The model considers the direct effect of both ownership-type dummy variables for SOE and FHS:

$$
\begin{aligned}
& \text { TE(SE, PTE) }=\alpha+\beta_{i} X_{i, t}+\varepsilon, \\
& X=\text { CAR, ERV, LCR, SOE, FHS. }
\end{aligned}
$$

The governance variables include the proportion of government shareholdings (SOE), and FHS. In fact, nearly all Taiwan's listed firms are either directly controlled or ultimately owned by the government through a pyramidal structure. We expect that the positive relation between capital expenditure and performance to be weaker in banks with a higher level of SOE than in banks with a lower level of SOE (Firth et al. 2008). CAR, LCR and ERV are as defined in Table 1.

\section{Results}

Table 2 provides the descriptive statistics for the related variables, the high standard deviations of all variables are being indicative of the structure of Taiwan's banking industry. The mean of the NPL reverse varying from NT\$509.26 million to NT\$1,178.6 million, the means of the fixed assets range from NT\$10,942.13 to NT\$12,032.12, the standard error is NT\$1,028.55 and ATFD range from NT 3,015.64 million to 3779.32. The calculated results clearly show the heterogeneity in bank characteristics, which evolve differently depending on bank size. The mean employees are 4,269 and the mean of ATFD is 3464.50 , as expected for trading activities during the period. In addition, the minimum is about 960.08 (untabled) and the value of $25,669.45$ for the liability. Branch has a mean of about 105.22 with a standard deviation of about 62.27 . The mean value for OD is 7.84 and the standard deviation is 3.0, while for the banking CAR, the mean and standard deviation are 12.33 and 4.39, respectively. The Pearson's correlation coefficients $(\gamma)$ between input-output which are positive in the profitability and marketability model are isotonic but untable reports here.

The profitability and marketability efficiency results are reported in Table 3 . For bank marketability efficiency, there are two indexes of efficiency for each bank (VRS and output-oriented). In a similar fashion, for profitability efficiency, there is only one index of efficiency for each bank (CRS and input-oriented). It can be seen that the mean scale efficiency scores $(0.69,0.70,0.88)$ are less than the TE scores $(0.86,0.88,0.69)$. 
Table 2. Descriptive statistics (2008-2012)

\begin{tabular}{|c|c|c|c|c|c|c|c|c|}
\hline \multirow{2}{*}{ Variables } & \multicolumn{2}{|c|}{ 2008-2009 } & \multicolumn{2}{|c|}{ 2010-2011 } & \multicolumn{2}{|c|}{2012} & \multicolumn{2}{|c|}{ 2008-2012 } \\
\hline & $\mu$ & $\sigma$ & $\mu$ & $\sigma$ & $\mu$ & $\sigma$ & $\mu$ & $\sigma$ \\
\hline Employees & 3458 & - & 3457 & - & 4256 & - & 4269 & 2602 \\
\hline Fixed assets $^{\mathrm{B}}$ & 11.10 & - & 10.94 & - & 12.31 & - & 12.03 & 1029 \\
\hline IT inputs $\left(\right.$ Budget $\left.^{\mathrm{M}}\right)$ & 488 & 309 & 52 & 116 & 190 & 424 & 217 & 376 \\
\hline IT inputs $\left(\mathrm{ATM}^{\mathrm{N}}\right)$ & 834 & - & 856 & - & 766 & - & 733 & 978 \\
\hline $\mathrm{ATFD}^{\mathrm{B}}$ & 3.02 & 2985 & 3.87 & 3.76 & 3.78 & 4.15 & 3.47 & 3.54 \\
\hline Deposit $^{\mathrm{B}}$ & 648.98 & 301.98 & 725.57 & 750.14 & 888.17 & 688.05 & 656.81 & 655.17 \\
\hline Liability $^{\mathrm{B}}$ & 27.97 & 13.95 & 18.01 & 19.16 & 26.00 & 18.39 & 25.67 & 18.94 \\
\hline NPL reverse ${ }^{B}$ & 0.92 & 0.93 & 1.18 & 1.08 & 5.09 & 8.39 & 6.71 & 11.49 \\
\hline CAR & 8.87 & - & 7.23 & - & 12.81 & - & 12.33 & 4.39 \\
\hline Branch $^{N}$ & 83.71 & - & 84.46 & - & 106.72 & - & 105.22 & 62.27 \\
\hline OD $\%$ & 7.7 & 8.7 & 8.4 & 8.6 & 8.1 & 3.4 & 7.84 & 3.0 \\
\hline
\end{tabular}

Notes: This table describes the sample of 28 commercial banks for the time period 2008-2012. All variables are as defined in Table 1. \$: NT\$ billion: B; Numbers: N; \%: ratio; @: coefficient; $\mu$ : mean.

The stage 2 results suggest a relatively high mean TE compared to SE. Indeed, the inclusion of risk in the calculation of banking efficiency scores show, on average, an increase. In Table 3 (also see Table 4), it is obvious that the mean of the profitability efficiency indexes is below $90 \%$, whereas those of the marketability measures are in comparatively lower levels, and the SE is $86.9 \%$ on average. The results show that the majority of these CBs are performing inefficiently in both stages. However, the minimum mean of the marketability efficiency indexes is TE at the $69 \%$ level, much lower than that of profitability efficiency $(=78.0 \%)$. This finding provides evidence suggesting a lower level of marketability, rather than the profitability.

In 2012, TE remained the same for 7 DMUs which have robust efficiency units in the profitability stage; however, this was much less for the marginally efficient units. In most of the distinctly inefficient units the DMU performance is not good. Based on the above results, it is clear that unless one controls for IT inputs and risk factors in the calculation it is easy to miscalculate the DMU inefficiency. It can be seen that noninterest income increases the expenses of dealing with economic activities, due to extra input, monitoring, negotiating costs, etc., reducing DMU efficiency. This shows that risk factors have an impact on DMU efficiency, which is consistent with the results obtained by Chiu et al. (2011), Hughes et al. (2001), and Ataullah et al. (2004).

From the efficiency reference set and according to results measured by VRS, it was found that of the DMU04, 10, 28 were the robustly efficient units throughout 20082012. The results reveal that risk factors and IT inputs influence their competitive efficiency in terms of operating diversification, branches and liability. Table 3 reports the estimates for inefficient banks from the network model in the first stage, such as the DMU 05. It can be seen that the profitability of TE is lower than the marketability of TE. 
Table 3. Value Chain DEA (1)

\begin{tabular}{|c|c|c|c|c|c|c|c|c|c|c|c|c|}
\hline \multirow{3}{*}{ DMU } & \multirow{2}{*}{\multicolumn{3}{|c|}{ Profitability TE }} & \multicolumn{9}{|c|}{ Marketability } \\
\hline & & & & \multicolumn{3}{|c|}{ 2008-2009 } & \multicolumn{3}{|c|}{ 2010-2011 } & \multicolumn{3}{|c|}{2012} \\
\hline & $\begin{array}{c}2008- \\
2009\end{array}$ & $\begin{array}{c}2010- \\
2011\end{array}$ & 2012 & TE & $\mathrm{SE}$ & Note & TE & SE & Note & $\mathrm{TE}$ & $\mathrm{SE}$ & Note \\
\hline A & 0.93 & 1 & 0.83 & 0.90 & 0.83 & $\uparrow$ & 1 & 0.72 & $\uparrow$ & 0.81 & 0.92 & $\downarrow$ \\
\hline $\mathrm{B}$ & 0.73 & 0.40 & 0.74 & 0.82 & 0.91 & $\begin{array}{c}\uparrow \\
\end{array}$ & 0.92 & 0.92 & $\bar{\uparrow}$ & 0.82 & 0.91 & $\downarrow$ \\
\hline $\mathrm{C}$ & 0.72 & 0.75 & 0.85 & 0.82 & 0.90 & $\uparrow$ & 0.82 & 0.92 & $\downarrow$ & 0.83 & 0.99 & $\uparrow$ \\
\hline $\mathrm{D}$ & 0.97 & 0.47 & 1 & 1 & 1 & $\boxminus$ & 1 & 1 & $\boxminus$ & 1 & 1 & $\boxminus$ \\
\hline $\mathrm{E}$ & 0.41 & 0.97 & 0.34 & 1 & 1 & $\boxminus$ & 1 & 1 & $\boxminus$ & 1 & 1 & $\boxminus$ \\
\hline $\mathrm{F}$ & 0.86 & 0.97 & 0.71 & 0.52 & 0.99 & $\downarrow$ & 1 & 0.73 & $\uparrow$ & 0.53 & 0.97 & $\downarrow$ \\
\hline$G$ & 0.92 & 1 & 0.53 & 0.75 & 0.19 & $\uparrow$ & 0.42 & 0.44 & $\uparrow$ & 0.16 & 0.86 & $\uparrow$ \\
\hline $\mathrm{H}$ & 0.90 & 1 & 0.70 & 1 & 0.32 & $\uparrow$ & 1 & 0.25 & $\uparrow$ & 1 & 0.32 & $\uparrow$ \\
\hline $\mathrm{I}$ & 1 & 0.54 & 0.00 & 1 & 1 & $\boxminus$ & 1 & 1 & $\boxminus$ & 1 & 1 & $\boxminus$ \\
\hline $\mathrm{J}$ & 1 & 0.86 & 0.64 & 0.69 & 0.84 & $\uparrow$ & 0.79 & 0.97 & $\downarrow$ & 0.68 & 0.86 & $\downarrow$ \\
\hline $\mathrm{K}$ & 0.74 & 0.92 & 0.57 & 0.77 & 0.80 & $\uparrow$ & 0.90 & 0.83 & $\uparrow$ & 0.66 & 0.94 & $\downarrow$ \\
\hline $\mathrm{L}$ & 0.73 & 1 & 0.67 & 0.91 & 0.76 & $\uparrow$ & 1 & 0.64 & $\uparrow$ & 0.82 & 0.85 & $\uparrow$ \\
\hline $\mathrm{M}$ & 0.83 & 1 & 0.73 & 0.85 & 0.36 & $\uparrow$ & 1 & 0.32 & $\uparrow$ & 0.31 & 0.97 & $\uparrow$ \\
\hline $\mathrm{N}$ & 1 & 0.45 & 1 & 0.76 & 0.36 & $\uparrow$ & 0.62 & 0.45 & $\uparrow$ & 0.30 & 0.92 & $\uparrow$ \\
\hline $\mathrm{O}$ & 1 & 1 & 1 & 0.77 & 0.40 & $\bar{\uparrow}$ & 0.71 & 0.45 & $\uparrow$ & 0.39 & 0.80 & $\bar{\uparrow}$ \\
\hline $\mathrm{P}$ & 0.55 & 0.60 & 0.60 & 0.83 & 0.80 & $\uparrow$ & 0.67 & 0.83 & $\uparrow$ & 0.67 & 0.98 & $\uparrow$ \\
\hline$Q$ & 1 & 0.50 & 1 & 0.68 & 0.59 & $\uparrow$ & 0.77 & 0.78 & $\uparrow$ & 0.41 & 0.98 & $\downarrow$ \\
\hline $\mathrm{R}$ & 1 & 0.99 & 0.76 & 0.76 & 0.40 & $\uparrow$ & 0.94 & 0.31 & $\uparrow$ & 0.32 & 0.87 & $\uparrow$ \\
\hline $\mathrm{S}$ & 1 & 0.39 & 0.70 & 0.93 & 0.73 & $\uparrow$ & 1 & 0.67 & $\uparrow$ & 0.82 & 0.82 & $\uparrow$ \\
\hline $\mathrm{T}$ & 0.89 & 0.63 & 0.75 & 0.92 & 0.59 & $\uparrow$ & 1 & 0.44 & $\uparrow$ & 0.61 & 0.89 & $\uparrow$ \\
\hline $\mathrm{U}$ & 0.95 & 0.00 & 0.74 & 0.86 & 0.59 & $\uparrow$ & 1 & 0.68 & $\uparrow$ & 0.56 & 0.92 & $\uparrow$ \\
\hline $\mathrm{V}$ & 0.86 & 1 & 0.59 & 0.91 & 0.34 & $\uparrow$ & 1 & 0.40 & $\uparrow$ & 0.53 & 0.59 & $\uparrow$ \\
\hline $\mathrm{W}$ & 0.86 & 1 & 0.63 & 0.91 & 0.42 & $\uparrow$ & 0.30 & 0.82 & $\downarrow$ & 0.71 & 0.54 & $\uparrow$ \\
\hline$X$ & 0.97 & 0.55 & 1 & 0.87 & 0.38 & $\uparrow$ & 1 & 0.26 & $\uparrow$ & 0.39 & 0.84 & $\uparrow$ \\
\hline $\mathrm{Y}$ & 1 & 1 & 1 & 1 & 1 & $\uparrow$ & 1 & 1 & $\boxminus$ & 1 & 1 & $\boxminus$ \\
\hline $\mathrm{Z}$ & 0.64 & 0.74 & 0.83 & 0.80 & 0.80 & $\downarrow$ & 0.88 & 0.83 & $\downarrow$ & 0.98 & 0.85 & $\downarrow$ \\
\hline$\Omega$ & 1 & 1 & 1 & 1 & 1 & $\boxminus$ & 1 & 1 & $\boxminus$ & 1 & 1 & $\boxminus$ \\
\hline$\Phi$ & 0.98 & 0.82 & 0.96 & 1.00 & 0.98 & $\downarrow$ & 1 & 0.82 & $\uparrow$ & 1 & 0.96 & $\downarrow$ \\
\hline $\mathrm{m}$ & 0.87 & 0.80 & 0.78 & 0.86 & 0.69 & & 0.88 & 0.70 & & 0.69 & 0.88 & \\
\hline
\end{tabular}

Notes: Efficiency strength is classified into four levels by Norman and Stoker (1991): (1) robustly efficient units are those where a DMU appears in the reference sets more than three times (TE, PTE, $\mathrm{SE}=1)$; (2) marginally efficient units are those where a DMU appears less than twice, although TE, $\mathrm{PTE}$ and $\mathrm{SE}=1$; (3) marginally inefficient units are those where the DMU efficiency is between 0.9 and 1, which means that the DMU will reach the relative efficiency only if inputs or outputs are improved; (4) distinctly inefficient units where the DMU (TE, PTE, SE are lower than 0.9) performance is not good. TE $=$ PTE $\times$ SE. TE: technical efficiency; PTE: pure technical efficiency; SE: scale efficiency; $\uparrow$ : increasing return to scale; $\downarrow$ : decreasing return to scale; $\boxminus$ : constant return to scale. IT budgets proxy for IT inputs. 
In Table 3, it can be seen that DMU09, 10, 14, 15, 17, 18, 19, 25, 27 all exhibited CRS during the global financial crisis (2008-2009). DMU11 was robustly efficient from 2010-2011, but other periods it was distinctly inefficient. The results indicate that traditional measures do not contribute to the productivity, while marketability is ineffective in terms of FI and operating efficiency. DMU11 could have benefited from lowering both labor and fixed assets by about 14.3\% (2010-2011) and 35.6\% (2012), respectively. The improvement in marketability can be attributed to better usage of deposits together with gains from non-interest activities, namely product availability and OD. The DMU08 is subject to local influences, serving Taichung City, so that the scale efficiency is still lower than that of other bands in the reference set $(0.32,0.25,0.32$ in Table 3 , and $0.76,0.51,0.88$ in Table 4). It can be concluded that this local bank which had experienced severe problems with FI and NPLs was able to recover. Interestingly, there is some evidence that banks which are efficient at transforming initial inputs into intermediate outputs tend to be less efficient at actualizing these into marketability. For instance, DMU14, 15,17,18, which fared badly in terms of transforming initial inputs into intermediate outputs (stage 1), turned out to be relatively profitable in transforming these into marketability (stage 2). This implies that while banks were inefficient in producing traditional operating activities (deposit to lending). Such services were appreciated by customers that adopted more innovative products and carried out high levels of transactions. Eventually, SE $=$ TE/PTE, which represents the proportion of inputs can be further reduced after elimination of pure technical inefficiency, if scale adjustments are possible. Those DMUs held the SE below 1, meaning that the scale is inefficient and there is potential input saving, including increases in the amount of trading on financial derivatives, deposits and liabilities through adjustment of the operational scale.

Due to the limited nature of our efficiency measure, ranging from 0 and 1 , we use the panel Tobit regression rather than ordinary least squares (OLS) method, which results are presented in Table 6. The impact of risk factors and CAR is examined. Then, SOE and FHS represent the intervention of managerial decisions is examined simultaneously (Chiu et al. 2011). The significantly marginal effect $=-2.879$ of LCR for TE and insignificant for PTE, SE. The results indicate that the LCR does not have an impact on a bank's PTE $(\beta=-4.32)$ and has no impact on SE $(\beta=0.32)$. The results support the moral hazard hypothesis (Chiu et al. 2008). Their findings show that the efficiency scores of banks with a high credit risk improved relatively more in comparison to banks with a lower credit risk. A bank with high LCR may show weakness, as the cost of these debts may weigh on the DMU and increase its default risk. In the untable calculation, LCR is more significantly correlated with NPL reverse $(\gamma=0.961)$ and branches $(\gamma=$ 0.259). This means that the increases in the LCR ratio will lead to the NPL reverse and branches, but there have no impact on the OD or liability. It can be seen from Table 5 that CAR has a significantly positive impact across all efficiencies, which implies that for all regulations promoted under the three pillars of Basel II, the higher capital stringency increases efficiency. These results suggest that the IT inputs and FI (operating environment) do indeed have a statistically significant influence on banks' performance. 
Table 4. Value Chain DEA (2)

\begin{tabular}{|c|c|c|c|c|c|c|c|c|c|c|c|c|}
\hline \multirow{3}{*}{ DMU } & \multirow{2}{*}{\multicolumn{3}{|c|}{ Profitability TE }} & \multicolumn{9}{|c|}{ Marketability } \\
\hline & & & & \multicolumn{3}{|c|}{ 2008-2009 } & \multicolumn{3}{|c|}{ 2010-2011 } & \multicolumn{3}{|c|}{2012} \\
\hline & $\begin{array}{c}2008- \\
2009\end{array}$ & $\begin{array}{c}2010- \\
2011\end{array}$ & 2012 & $\mathrm{TE}$ & $\mathrm{SE}$ & Note & $\mathrm{TE}$ & SE & Note & $\mathrm{TE}$ & $\mathrm{SE}$ & Note \\
\hline A & 0.93 & 0.83 & 0.84 & 0.87 & 0.92 & $\uparrow$ & 1 & 0.79 & $\uparrow$ & 1 & 0.66 & $\uparrow$ \\
\hline B & 0.73 & 0.71 & 0.71 & 0.73 & 0.90 & $\downarrow$ & 0.88 & 0.92 & $\uparrow$ & 0.73 & 0.91 & $\downarrow$ \\
\hline $\mathrm{C}$ & 0.72 & 0.77 & 0.79 & 0.73 & 0.99 & $\bar{\uparrow}$ & 0.81 & 0.93 & $\downarrow$ & 0.80 & 0.86 & $\downarrow$ \\
\hline $\mathrm{D}$ & 0.97 & 0.56 & 1 & 1 & 1 & $\boxminus$ & 1 & 1 & $\boxminus$ & 1 & 1 & $\boxminus$ \\
\hline $\mathrm{E}$ & 0.41 & 0.41 & 0.33 & 1 & 1 & $\boxminus$ & 1 & 1 & $\boxminus$ & 0.72 & 0.99 & $\downarrow$ \\
\hline $\mathrm{F}$ & 0.86 & 0.72 & 0.71 & 0.60 & 0.93 & $\downarrow$ & 1 & 0.96 & $\uparrow$ & 1 & 0.69 & $\uparrow$ \\
\hline $\mathrm{G}$ & 0.92 & 0.70 & 0.53 & 0.42 & 0.99 & $\uparrow$ & 0.57 & 0.62 & $\uparrow$ & 0.37 & 0.58 & $\uparrow$ \\
\hline $\mathrm{H}$ & 0.90 & 0.83 & 0.70 & 1 & 0.76 & 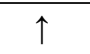 & 1 & 0.51 & $\bar{\uparrow}$ & 0.42 & 0.88 & $\uparrow$ \\
\hline $\mathrm{I}$ & 1 & 0.99 & 1 & 1 & 1 & $\boxminus$ & 1 & 1 & $\boxminus$ & 1.00 & 1 & $\boxminus$ \\
\hline $\mathrm{J}$ & 1 & 0.90 & 0.77 & 0.81 & 0.82 & $\downarrow$ & 1 & 1 & $\boxminus$ & 0.76 & 0.90 & $\downarrow$ \\
\hline $\mathrm{K}$ & 0.74 & 0.68 & 0.54 & 0.75 & 0.99 & $\downarrow$ & 0.87 & 0.96 & $\uparrow$ & 0.75 & 0.99 & $\downarrow$ \\
\hline $\mathrm{L}$ & 0.73 & 0.72 & 0.67 & 0.61 & 0.89 & $\uparrow$ & 0.96 & 0.58 & $\uparrow$ & 0.55 & 1 & $\boxminus$ \\
\hline $\mathrm{M}$ & 0.83 & 0.84 & 0.73 & 0.32 & 1 & $\downarrow$ & 1 & 0.34 & $\bar{\uparrow}$ & 0.35 & 1 & $\downarrow$ \\
\hline $\mathrm{N}$ & 1 & 1 & 1 & 0.89 & 0.99 & $\bar{\uparrow}$ & 1 & 0.98 & $\bar{\uparrow}$ & 1 & 0.50 & $\bar{\uparrow}$ \\
\hline $\mathrm{O}$ & 1 & 1 & 1 & 0.92 & 0.92 & $\uparrow$ & 1 & 0.83 & $\uparrow$ & 0.59 & 0.88 & $\uparrow$ \\
\hline $\mathrm{P}$ & 0.55 & 0.71 & 0.58 & 0.52 & 0.99 & $\bar{\uparrow}$ & 0.68 & 0.82 & $\bar{\uparrow}$ & 0.58 & 1 & $\downarrow$ \\
\hline $\mathrm{Q}$ & 1 & 0.82 & 0.67 & 1 & 1 & $\boxminus$ & 1 & 1 & $\boxminus$ & 0.65 & 1 & $\downarrow$ \\
\hline $\mathrm{R}$ & 1 & 0.94 & 0.71 & 0.87 & 1 & $\uparrow$ & 1 & 0.84 & $\uparrow$ & 0.46 & 0.91 & $\bar{\uparrow}$ \\
\hline $\mathrm{S}$ & 1 & 1 & 1 & 1 & 0.87 & $\uparrow$ & 1 & 0.93 & $\uparrow$ & 0.98 & 1 & $\downarrow$ \\
\hline $\mathrm{T}$ & 0.89 & 0.80 & 0.69 & 1 & 1 & $\boxminus$ & 1 & 0.63 & $\uparrow$ & 0.67 & 0.96 & $\bar{\uparrow}$ \\
\hline $\mathrm{U}$ & 0.95 & 0.76 & 0.71 & 0.80 & 0.98 & $\uparrow$ & 0.99 & 0.79 & $\uparrow$ & 0.58 & 0.97 & $\uparrow$ \\
\hline $\mathrm{V}$ & 0.86 & 0.69 & 0.59 & 0.69 & 0.72 & $\uparrow$ & 1 & 0.68 & $\uparrow$ & 0.51 & 0.97 & $\uparrow$ \\
\hline $\mathrm{W}$ & 0.86 & 0.75 & 0.57 & 1 & 1 & $\uparrow$ & 1 & 1 & $\boxminus$ & 0.23 & 0.90 & $\downarrow$ \\
\hline$X$ & 0.97 & 1 & 1 & 0.50 & 0.94 & $\uparrow$ & 1 & 0.48 & $\uparrow$ & 1 & 0.48 & $\uparrow$ \\
\hline $\mathrm{Y}$ & 1 & 0.83 & 1 & 1 & 1 & $\boxminus$ & 1 & 1 & $\boxminus$ & 1 & 0.85 & $\downarrow$ \\
\hline $\mathrm{Z}$ & 0.82 & 0.87 & 0.87 & 0.88 & 0.93 & $\downarrow$ & 0.99 & 0.88 & $\downarrow$ & 0.87 & 0.99 & $\downarrow$ \\
\hline$\Omega$ & 1 & 1 & 1 & 1 & 1 & $\boxminus$ & 1 & 1 & $\boxminus$ & 1 & 1 & $\boxminus$ \\
\hline$\Phi$ & 0.75 & 0.78 & 0.86 & 0.88 & 0.85 & $\downarrow$ & 1 & 0.78 & $\uparrow$ & 1 & 0.86 & $\downarrow$ \\
\hline $\mathrm{m}$ & 0.87 & 0.81 & 0.77 & 0.81 & 0.94 & & 0.96 & 0.83 & & 0.74 & 0.88 & \\
\hline
\end{tabular}

Notes: TE $=$ PTE $\times$ SE. TE: Technical efficiency; PTE: pure technical efficiency; SE: scale efficiency; $\uparrow$ : increasing return to scale; $\downarrow$ : decreasing return to scale; $\boxminus$ : constant return to scale. ATM proxy for IT budgets. 
We find that the economic uncertainty (volatility proxy) variables have some effect on inefficiency in our study. ERV has a significantly negative coefficient for SE and PTE, but a significantly positive coefficient for TE. The results suggest that great volatility leads to an increase of ATFD (input) and liability or NPL reverse (output). There is a negative relation in SE and PTE, showing that the clear effect on the OD will be concentrated and the number of branches can be reduced in a varied environment. The results are consistent with the bad risk management hypothesis, suggesting that technical efficiency precedes reductions in problem loans. Otherwise, the greater IRV will hamper the PTE and lower the SE due to bad risk management. External shocks always intervene in the internal process, lowering the operating efficiency, so that risk management is not good.

Basel II \& III contain regulations that enhance the monitoring effect, for example, the role of SOEs in forcing banks to disclose accurate information to the public, and creating powerful official surveillance agencies (Barth et al. 2004). We find that SOE is positively related to efficiency, and has marginal effects on the scale efficiency $(10.2 \%)$. Our explanation for this is that the greater quantity of funds provided by a system that enhances IT and networks through accounting and auditing requirements might improve the abilities of surveillance to intervene in managerial decisions in an uncertain environment. The results in Table 6 indicate that once we control the ownership-type in each CB (FHS or non-FHS). FHS has a positive and statistically significant influence on most efficiency. This finding suggests that the subsidiary contributes to the conglomerate as an internal capital market. Improved information availability increases the potential pool of customers, making it easier for a collaborative-sales force to identify and assist them. This can obviously have a positive effect on TE as well.

Table 5. Tobit regression: the relationship between risk factors and DMU efficiency

\begin{tabular}{lccc}
\hline \multicolumn{1}{c}{ Variables } & TE & SE & PTE \\
\hline Constant & $3.58^{* * *}$ & $3.50^{*}$ & 5.19 \\
& $(2.03)$ & $(1.698)$ & $(1.34)$ \\
\hline CAR & $0.02^{*}$ & $0.05^{* * *}$ & $0.08^{* * *}$ \\
Capital adequacy ratio & $(1.89)$ & $(3.34)$ & $(2.66)$ \\
\hline ERV & $0.32^{* *}$ & $-0.39^{* * *}$ & $-0.88^{* * *}$ \\
Exchange rate volatility & $(2.03)$ & $(-3.06)$ & $(-3.47)$ \\
\hline IRV & 0.03 & $-0.116^{* * *}$ & $-0.38^{* * *}$ \\
Interest rate volatility & $(0.82)$ & $(-3.05)$ & $(-2.84)$ \\
\hline LCR & $-2.88^{*}$ & 0.32 & -4.57 \\
Loan of capital ratio & $(-1.79)$ & $(1.31)$ & $(-1.18)$ \\
\hline SOE & $0.16^{* *}$ & $0.12^{*}$ & 0.17 \\
State-own enterprise & $(2.25)$ & $(1.94)$ & $(1.49)$ \\
\hline FHS & $0.20^{* * *}$ & $0.12^{*}$ & $0.19^{*}$ \\
Financial holding subsidiary & $(2.94)$ & $(1.94)$ & $(1.89)$ \\
\hline$\chi^{2}$ & 13.6 & 45.9 & 31.4 \\
p-value & $(0.03)$ & $(0.00)$ & $(0.00)$ \\
\hline
\end{tabular}




\section{Managerial implications and conclusions}

The empirical results show the importance of incorporating IT and financial derivatives into the analysis of Value-Chain DEA in Taiwan's banking industry. It has been shown that there are always inefficient areas existing in some operating processes. There are two major contributions of this paper. We first show the appeal of dividing commercial bank operations into two distinct stages: profitability and marketability. The intermediary variables are the ATFD, deposits and liabilities that represent a common effect to combine both efficiencies of profitability and marketability in the banking system. It is found that most DMUs need to generate increasing returns to scale in ATFD and IT inputs. Second, the two-stage DEA method can potentially be used to test risk control in DMUs which contribute the value-chain efficiency of their units to the overall operating environment.

The major limitation affecting this study concerns the data set. Some proxy measures may not fully capture the risk factors, for example, the party-related transaction among subsidiaries in the conglomerate where data were not available. Future research can compare the productivity performance of commercial banks across various operating activities (e-business, credit cards, stock transactions, etc.) and the multi-stage system is best way (Kao 2014). The results support the bad risk management hypothesis, suggesting that technical efficiency precedes a reduction in problem loans, concentration of the operating items and condensing branches in relation to developing information technology and utilization of financial derivatives. The ratio of long-term loans to total capital has the capacity to recover non-performing loans and help for branches (local bank insufficient their distributions) in the moral hazard hypothesis.

\section{Acknowledgements}

The authors would like to thank the anonymous referees for their several helpful comments which have helped to improve the quality of this manuscript. The remaining errors and omissions are the responsibility of the authors alone.

\section{References}

Agoraki, M.; Delis, M. D.; Pasiouras, F. 2011. Regulations, competition and bank risk-taking in transition countries, Journal of Financial Stability 7(1): 38-48.

http://dx.doi.org/10.1016/j.jfs.2009.08.002

Akther, S.; Fukuyama, H.; Weber, W. L. 2012. Estimating two-stage network slacks-based inefficiency: an application to Bangladesh banking, Omega 41(1): 88-96.

http://dx.doi.org/10.1016/j.omega.2011.02.09

Ataullah, A.; Cockerill, T.; Lee, H. 2004. Financial liberalization and bank efficiency: a comparative analysis of India and Pakistan, Applied Economics 36(17): 1915-924.

http://dx.doi.org/10.1080/000368404200068638

Banker, R. D.; Charnes, A.; Cooper, W. W. 1984. Some models for estimating technical and scale inefficiencies in data envelopment analysis, Management Science 30(9): 1078-1092.

http://dx.doi.org/10.1287/mnsc30.9.1078 
Banker, R. D.; Chang, H.; Lee, S. 2010. Differential impact of Korean banking system reforms on bank productivity, Journal of Banking and Finance 34(7): 1450-1460.

http://dx.doi.org/10.1016/j.jbankfin.2010.02.02

Barth, J. R.; Caprio Jr, G.; Levine, R. 2004. Bank regulation and supervision: what works best?, Journal of Financial Intermediation 13(2): 205-248. http://dx.doi.org/10.1016/j.jfi.2003.06.002

Berger, A. N.; DeYoung, R. 1997. Problem loans and cost efficiency in commercial banks, Journal of Banking and Finance 21(6): 849-870. http://dx.doi.org/10.1016/S0378-4266(97)00003-4

Bolt, W.; Tieman, A. F. 2004. Banking competition, risk and regulation, Scandinavian Journal of Economics 106(4): 783-804. http://dx.doi.org/10.1111/j.0347-0520.2004.00388.X

Chang, T. C.; Chiu, Y. H. 2006. Affecting factors on risk-adjusted efficiency in Taiwan's banking industry, Contemporary Economic Policy 24(4): 634-648. http://dx.doi.org/10.1093/cep/by 1008

Charnes, A.; Cooper, W. W.; Rhodes, E. 1978. Measuring the efficiency of decision making units, European Journal of Operational Research 2(6): 429-444.

http://dx.doi.org/10.1016/0377-2217(78)90138-8

Chen, K. 2012. Incorporating risk input to the analysis of bank productivity: application to the Taiwanese banking industry, Journal of Banking and Finance 36(7): 1911-1927.

http://dx.doi.org/10.1016/j.jbankfin.2012.02.012

Chen, Y.; Zhu, J. 2004. Measuring information technology's indirect impact on firm performance, Information Technology and Management 5(1-2): 9-22.

http://dx.doi.org/10.1023/B:ITEM.0000008075.43543.97

Chiu, Y.; Jan, C.; Shen, D.; Wang, P. 2008. Efficiency and capital adequacy in Taiwan banking: BCC and Super-DEA estimation, The Service Industries Journal 28(4): 479-496.

http://dx.doi.org/10.1080/02642060801917604

Chiu, Y.; Chen, Y.; Bai, X. 2011. Efficiency and risk in Taiwan banking: SBM super-DEA estimation, Applied Economics 43(5): 587-602. http://dx.doi.org/1080/00036840802599750

Cook, W.; Tone, K.; Zhu, J. 2014. Data envelopment analysis: prior to choosing a model, Omega 44: 1-4. http://dx.doi.org/10.1016/j.omega.2013.09.004

Drake, I.; Hall, M. J. B. 2003. Efficiency in Japanese banking: an empirical analysis, Journal of Banking and Finance 27(5): 891-917. http://dx.doi.org/10.1016?S0378-4266(02)00240-6

Ebrahimnejad, A.; Tavana, M.; Hosseinzadeh, L.; Shahverdi, R.; Yousefpour, M. 2014. A threestage data envelopment analysis model with application to banking industry, Measurement 49: 308-319. http://dx.doi.org/10.1016/j.measurement. 2013.11.047

Firth, M.; Lin, C.; Wong, S. M. L. 2008. Leverage and investment under a state-owned bank lending environment: evidence from China, Journal of Corporate Finance 14(5): 642-653.

http://dx.doi.org/10.1016/j.jcorpfin.2008.08.002

Fukuyama, H.; Weber, W. L. 2010. A slacks-based inefficiency measure for a two-stage system with bad outputs, Omega 38(5): 398-409. http://dx.doi.org/10.1016/j.omega.2009.10.006

Gaganis, C.; Liadaki, A.; Doumpos, M.; Zopounidis, C. 2009. Estimating and analyzing the efficiency and productivity of bank branches, Managerial Finance 35(2): 202-218.

http://dx.doi.org/10.1108/03074350910923518

Glass, J. C.; Mckilop, D. G.; Morikawa, Y. 1998. Intermediation and value-added models for estimating cost economies in large Japanese bank 1977-1993, Applied Financial Economics 8(6): 653-661. http://dx.doi.org/10.1018/096031098332691

Hughes, J. P.; Mester, L. J.; Moon, C. G. 2001. Are scale economies in banking elusive or illusive? Evidence obtained by incorporating capital structure and risk-taking into models of bank production, Journal of Banking and Finance 25(12): 2169-2208.

http://dx.doi.org/10.1016/S0378-4266(01)00190-X 
Kao, C.; Hwang, S. 2008. Efficiency decomposition in the two-stage data envelopment analysis: an application to non-life insurance companies in Taiwan, European Journal of Operation Research 185(1): 418-429. http://dx.doi.org/10.1016/j.ejor.2006.11.041

Kao, C.; Hwang, S. 2010. Efficiency measurement for network systems: IT impact on firm performance, Decision Support System 48(3): 437-446. http://dx.doi.org/10.1016/j.dss.2009.06.002

Kao, C. 2014. Efficiency decomposition for general multi-stage systems in data envelopment analysis, European Journal of Operation Research 232(1): 117-124.

http://dx.doi.org/10.1016/j.ejor.2013.07.012

Kao, C. 2014. Efficiency decomposition in network data envelopment analysis with slacks-based measures, Omega 45: 1-6. http://dx.doi.org/10.1016/j.omega.2013.12.002

Lepetit, L.; Nys, E.; Rous, P.; Tarzi, A. 2008. Bank income structure and risk: an empirical analysis of European banks, Journal of Banking and Finance 32(8): 1452-1467.

http://dx.doi.org/10.1016/j.jbankfin.2007.12.002

Lieu, P.; Yeh, T.; Chiu, Y. 2005. Off-balance sheet activities and cost inefficiency in Taiwan's banks, The Service Industry Journal 25(7): 925-944. http://dx.doi.org/10.1080/02642060500134196

Liu, J.; Lu, L.; Lu, W.; Lin, B. 2013. Data envelopment analysis 1978-2010: a citation-based literature survey, Omega 41(1): 3-15. http://dx.doi.org/10.1016/j.omega.2010.12.006

Luo, X. 2003. Evaluating the profitability and marketability efficiency of large banks: an application data envelopment analysis, Journal of Business Research 56(8): 627-635.

http://dx.doi.org/10.1016/S0148-2963(01)00293-4

Paradi, J. C.; Zhu, H. A. 2013. Survey on bank branch efficiency and performance research with data envelopment analysis, Omega 41(1): 61-79. http://dx.doi.org/10.1016/j.omega.2011.08.010

Park, K. H.; Weber W. L. 2006. Profitability of Korean banks: test of market structure versus efficient structure, Journal of Economics and Business 58(3): 222-239.

http://dx.doi.org/10.1016/j.jeconbus.2005.09.003

Sealey, C.; Lindley, J. 1977. Inputs, outputs, and a theory of production and cost at depository financial institutions, Journal of Finance 32(4): 1251-1266.

http://dx.doi.org/10.1111/j.1540-6261.1977tb03324-X

Shao, B. B. M.; Lin, W. T. 2002. Technical efficiency analysis of information technology investments: a two-stage empirical investigation, Information and Management 39(5): 391-461. http://dx.doi.org/10.1016/S0378-7206(01)00105-7

Wang, C. H.; Gopal, R.; Aionts, S. 1997. Use of data envelopment analysis in assessing information technology impact on firm performance, Annals of Operation Research 73: 191-213. http://dx.doi.org/10.1023/A:1018977111455.

Mu-Shun WANG is an Associate Professor in the Department of Banking and Finance at Kainan University and major in the technological valuation and project finance in the field of research include performance management, financial management and financial econometrics

Shih-Tong LU is an Associate Professor in the Department of Banking and Finance at Kainan University and Adjunct Associate Professor at National Central University. He specializes in project management, risk management and performance management. 